\title{
Effect of ion implantation doping on electrical properties of yttria-stabilized zirconia thin films
}

\author{
B.A. van Hassel and A.J. Burggraaf \\ Laboratory for Inorganic Chemistry, Materials Science and Catalysis, Department of Chemical Technology, \\ University of Twente, P.O. Box 217, 7500 AE Enschede, The Netherlands
}

Received 20 December 1990; accepted for publication 3 June 1992

\begin{abstract}
The change in conductivity of Fe and Ti implanted rf-sputtered layers of yttria-stabilized zirconia (YSZ) was studied as a function of the temperature $\left(400-800^{\circ} \mathrm{C}\right.$ ) and oxygen partial pressure. In an oxidized state and in the temperature range of $400-$ $600^{\circ} \mathrm{C}$, the conductivity of the Fe implanted YSZ film $\left(15 \mathrm{keV}, 8 \times 10^{16} \mathrm{at.cm}^{-2}\right)$ was dominated by the $n$-type electronic conductivity of a thin $\mathrm{Fe}_{2} \mathrm{O}_{3}$ layer with an estimated thickness of less than $2 \mathrm{~nm}$ on top of the YSZ thin film. Due to the incorporation of a part of the implanted $\mathrm{Fe}$ atoms in the yttria-stabilized zirconia lattice, the ionic conductivity was somewhat decreased. In a reducing atmosphere this electronic conduction was no longer observed. In an oxidized state, the conductivity of the YSZ film was not influenced by the implantation of $\mathrm{Ti}\left(15 \mathrm{keV}, 8 \times 10^{16} \mathrm{at}_{\mathrm{cm}}^{-2}\right)$. After reduction in a $\mathrm{H}_{2}$ atmosphere, an increase in the conductivity of the sputtered film with 2-3 orders of magnitude was observed. This has been ascribed to the presence of nonstoichiometric $\mathrm{TiO}_{2-x}$, which is an $n$-type semiconductor.
\end{abstract}

\section{Introduction}

Yttria-stabilized zirconia (YSZ) is an important oxygen ion conducting solid electrolyte [1]. Both ceramic bulk materials and thin films deposited by sputtering $[2,3]$ or chemical vapour deposition $[4,5]$, are used in applications like oxygen sensors, oxygen pumps and fuel cells [6]. The exchange of oxygen between the gas and the electrolyte can be described with the following overall reaction:

$\mathrm{O}_{2}(\mathrm{~g})+2 \mathrm{~V}_{\mathrm{O}}^{\ddot{1}}+4 \mathrm{e}^{-}=2 \mathrm{O}_{\mathrm{O}}^{\times}$,

where, in Kröger-Vink notation, $\mathrm{O}_{\mathrm{O}}^{\times}$is a normal $\mathrm{O}^{2-}$ ion in the yttria-stabilized zirconia lattice and, $v_{o}$ an oxygen-ion vacancy. When noble metal electrodes are used, the exchange of oxygen between the gas phase and the solid electrolyte is geometrically limited to regions near to the three phase boundary between the oxygen gas, solid electrolyte and electronic conductor.

Mixed conducting oxides, which exhibit as high an ionic and electronic conductivity as possible, have advantages in comparison with the presently used electronic conductors [7-9]. With good mixed con- ducting oxides, the electrochemical exchange of oxygen would occur over the entire electrode-gas interfacial area in which both oxygen ions and electrons are mobile. The large increase in the reaction area will significantly decrease the electrode polarization and hence the efficiency losses at the electrode, $\mathrm{O}_{2}$ (gas)/solid electrolyte interface.

Mixed conducting zirconia-based electrodes $[10,11]$ have advantages in comparison with other mixed conducting oxides in terms of the chemical and mechanical stability of the electrode-electrolyte interface. As both the chemical composition and thermal expansion are similar to the electrolyte itself it is expected that the integrity of the electrode-electrolyte interface can easily be maintained.

The electrode materials should also show good catalytic activity for the electrochemical oxidation of $\mathrm{H}_{2}$ and other fuel gases, if used as anode, and for the electrochemical reduction of $\mathrm{O}_{2}$ if used as cathode. The costs of the electrode material should be low and the lifetime as long as possible.

Previous publications [12-14] reported on efforts to develop mixed conducting electrode materials by doping yttria-stabilized zirconia with transition metal 
oxides [12-14]. In this paper the mixed conductivity of the implanted layers is studied. The layers were prepared through implantation of the corresponding transition metal ions into stabilized zirconia thin films, which were deposited on insulating $\mathrm{Al}_{2} \mathrm{O}_{3}$ substrates. This procedure was followed in order to increase the contribution of the ion implanted part of the yttria-stabilized zirconia substrate to the total conductivity of the ion implanted sample. If a bulk ceramic yttria-stabilized zirconia substrate is used it is possible that the ionic conductivity of the not implanted part of this substrate would have dominated the total conductivity of the sample.

As ion implantation is a non-equilibrium process, it has the capability of producing materials with compositions and microstructures unattainable by conventional ceramic techniques. In this study, for example, concentrations of the implanted ions are obtained which are far beyond the limit corresponding to the equilibrium solid solubility level. High concentrations of the transition metal oxide may be necessary in order to obtain the desired effects.

\section{Experimental}

Yttria-stabilized zirconia thin films $(65-108 \mathrm{~nm})$ were deposited on polished polycrystalline alumina substrates by rf-sputtering in a Leybold-Hereaus $\mathbf{Z}$ 500 apparatus. The cathode was made of finely powdered yttria-stabilized zirconia (composition: $\left(\mathrm{ZrO}_{2}\right)_{0.83}\left(\mathrm{YO}_{1.5}\right)_{0.17}$, called ' $\mathrm{ZY} 17$ ') using polyvinylalcohol as binder [15]. The plasma atmosphere was a mixture of argon and oxygen ( 82 and $18 \%$, respectively) and the total pressure was stabilized at $1.5 \times 10^{-2}$ mbar. All the deposits were made at a constant discharge power of $540 \mathrm{~W}$ and with a bias voltage of $120 \mathrm{~V}$. A deposition rate of $1.6 \AA / \mathrm{s}$ was obtained. After deposition the samples were annealed at $900^{\circ} \mathrm{C}$ in air during one hour.

The Fe or Ti doping of the layer was accomplished by ion implantation. The ion implantations were performed at room temperature in a vacuum of $4 \times 10^{-7}$ Torr. The YSZ films were implanted perpendicular to the sample surface at a beam current density of $2 \mu \mathrm{A} \mathrm{cm} \mathrm{cm}^{-2}$ using the isotope separator of the Laboratory for General Physics (LAN) of the State University of Groningen. For the hot cathode ion source $\mathrm{FeCl}_{2} \cdot 4 \mathrm{H}_{2} \mathrm{O}$ (Merck, p.a.) was used as feed material for $\mathrm{Fe}$ implantations. For the $\mathrm{Ti}$ implantation heated $\mathrm{TiO}_{2}$ (BDH Chemicals Ltd.) was chlorinated in situ with carbon tetrachloride.

The compositions and thickness of the stabilized zirconia thin films were analyzed by Rutherford Backscattering (RBS) using a 2 or $3 \mathrm{MeV}{ }^{4} \mathrm{He}$ ion beam. All measurements were carried out with a scattering angle $(\theta)$ of $165^{\circ}$ in the laboratory frame of reference, and with the analyzing beam perpendicular to the sample's surface. The mean composition of the Fe and $\mathrm{Ti}$ implanted films in terms of cation concentration ratio's was determined from the area under the appropriate signals, taking into account the corresponding differential scattering cross sections of the cations. The stopping cross section of the compound YSZ target was calculated from the atomic composition according to Bragg's rule [16], enabling the RBS energy scale to be translated into a depth scale $\left(\mathrm{at} . \mathrm{cm}^{-2}\right)$. The at.cm ${ }^{-2}$ depth scale was recalculated in $\mathrm{nm}$ by assuming that the atomic density was the same as that for crystalline yttria-stabilized zirconia. Corrections were applied for the limited energy resolution of the surface barrier detector ( $26 \mathrm{keV}$ (FWHM)), and for the range straggling (i.e. statistical broadening in the energy distribution due to multiple interactions) of the scattered ions [16].

Four rectangular shaped platinum electrodes were painted on the surface of the film, as shown in fig. 1. The platinum electrodes were sintered in air at $850^{\circ} \mathrm{C}$ during one hour. Four platinum point electrodes were spring loaded on these painted elec-

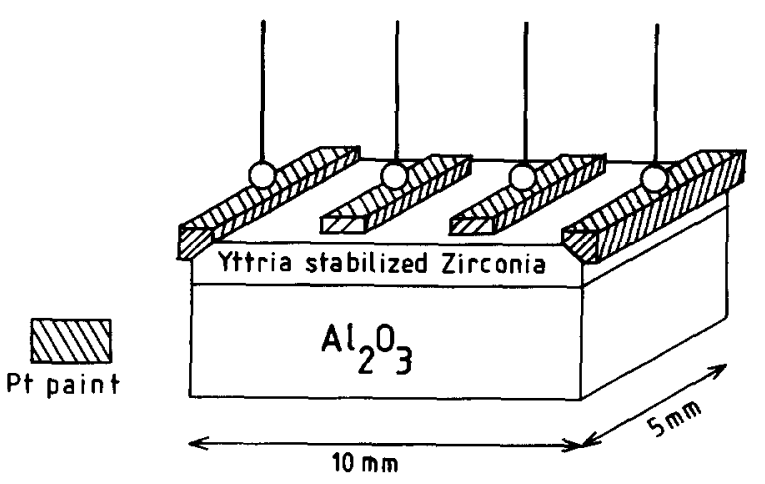

Fig. 1. Electrode geometry for the four point probe conductivity measurements. 
trodes. All samples were oxidized in air at $850^{\circ} \mathrm{C}$ prior to the four-point probe conductivity measurements, which were performed in a $\mathrm{N}_{2}\left(P_{\mathrm{O}_{2}}=1 \times\right.$ $\left.10^{-5} \mathrm{~atm}\right)$ or $\mathrm{H}_{2}\left(P_{\mathrm{O}_{2}}=1 \times 10^{-25} \mathrm{~atm}\right)$ atmosphere in the temperature range of $400-800^{\circ} \mathrm{C}$. The current between the two outer electrodes was delivered by the internal power supply of a Keithley 617 electrometer, which also measured the potential difference between the two inner potential probes. The current was measured with a Keithley 616 electrometer. The resistance was determined from the slope of the steady-state current versus potential plot.

\section{Results}

\subsection{Composition analysis}

Fig. 2 shows RBS spectra observed on yttria-stabilized zirconia thin films, both before and after the implantation of Fe or $\mathrm{Ti}\left(15 \mathrm{keV}, 8 \times 10^{16} \mathrm{at}^{.} \mathrm{cm}^{-2}\right)$. The vertical arrows indicate the energy of ${ }^{4} \mathrm{He}$ ions scattered from surface atoms of $\mathrm{Hf}, \mathrm{Zr}+\mathrm{Y}, \mathrm{Fe}, \mathrm{Ti}$, $A l$ and $O$, respectively. Hf was present as an impurity ( $2 \mathrm{wt} . \%)$ in the sputtering target of yttria-stabilized zirconia from which the stabilized-zirconia thin film was deposited. Under the experimental conditions, the energy edges of ${ }^{4} \mathrm{He}$ ions scattered from surface atoms of $\mathrm{Y}$ or $\mathrm{Zr}$ could not be resolved. The signal of ${ }^{4} \mathrm{He}$ scattered from $\mathrm{Al}$ is shifted towards lower energy in comparison with the energy edge of ${ }^{4} \mathrm{He}$ scattered from surface atoms of $\mathrm{Al}$ because of the energy loss in the yttria-stabilized zirconia layer.

As can be seen in figs. $2 b$ and $2 c$ the depth profile of the implanted $\mathrm{Fe}$ and $\mathrm{Ti}$ ions extends over approximately the whole thickness of the YSZ sputtered film. This is somewhat unexpected as RBS measurements [17,18] from Fe and Ti implanted bulk ceramic discs $\left(15 \mathrm{keV}, 8 \times 10^{16} \mathrm{at}_{\mathrm{cm}}^{-2}\right)$ revealed and $\mathrm{Fe}$ and $\mathrm{Ti}$ depth profile extending to a

Fig. 2. RBS spectra ( $2 \mathrm{MeV}{ }^{4} \mathrm{He}, \theta=165^{\circ}$, normal incidence, $2.3 \mathrm{keV} /$ channel) of thin films of yttria-stabilized zirconia on $\alpha$ aluminium oxide substrates: (a) non-implanted; (b) after implantation of $15 \mathrm{keV} \mathrm{Fe}$ up to a dose of $8 \times 10^{16} \mathrm{at.cm}-2$; (c) after implantation of $15 \mathrm{keV}$ Ti up to a dose of $8 \times 10^{16} \mathrm{at}_{\mathrm{cm}} \mathrm{cm}^{-2}$. The thickness of the YSZ sputtered films as determined from the RBS spectra in figs. a, b and c amount to 108,79 and $104 \mathrm{~nm}$, respectively.

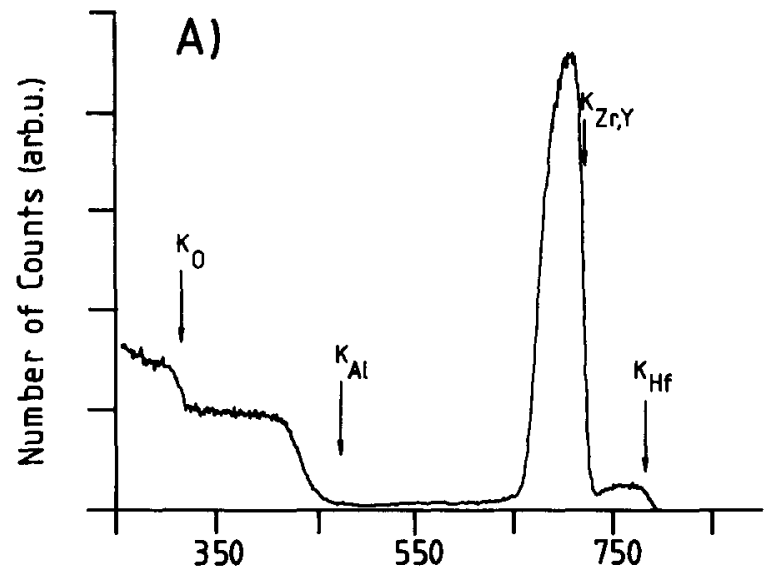

Channel Number

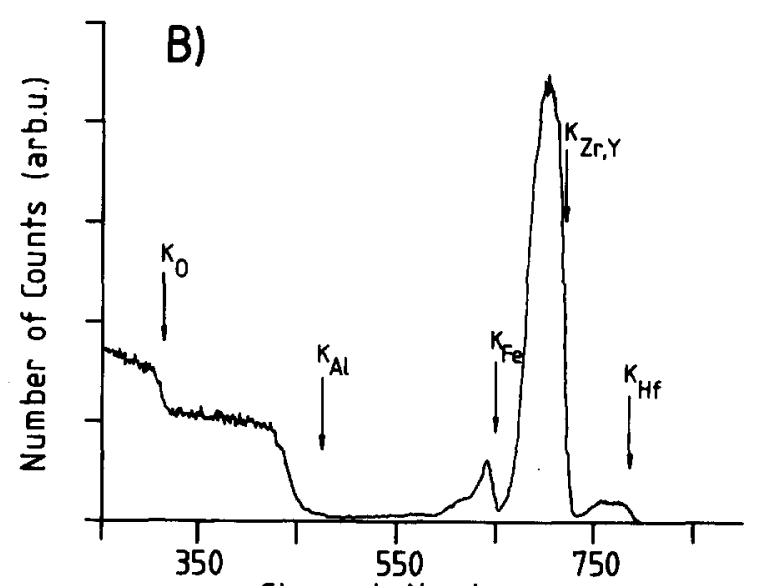

Channel Number

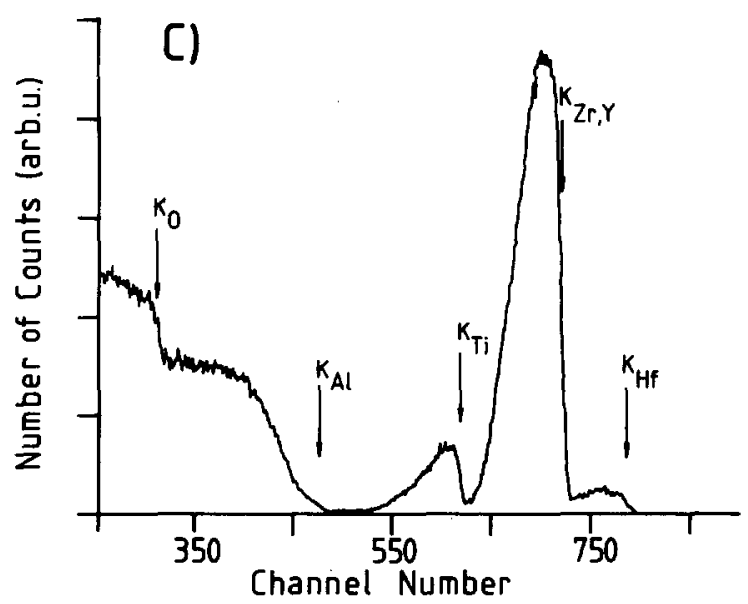


Table 1

Composition of yttria-stabilized zirconia films and their final thickness after the Fe and Ti implantation, as used for the conductivity measurements. $N_{\mathrm{Y}}, N_{\mathrm{Zr}}, N_{\mathrm{Fe}}$ and $N_{\mathrm{Ti}}$ represent the total number of $\mathrm{Y}, \mathrm{Zr}$, Fe or Ti atoms in the layer, as determined by $\mathrm{Rutherford}$ Backscattering (RBS). The ratio $\left(N_{\mathrm{Y}} /\left(N_{\mathrm{Y}}+N_{\mathrm{Zr}}\right)\right)=0.17$ resulted from X-ray fluorescence (XRF).

\begin{tabular}{|c|c|c|c|c|}
\hline Ion & $\begin{array}{l}\text { Energy } \\
(\mathrm{keV})\end{array}$ & $\begin{array}{l}\text { Dose } \\
(\text { at.cm } \\
-2)\end{array}$ & Composition & $\begin{array}{l}\text { Thickness } \\
\text { (nm) }\end{array}$ \\
\hline- & - & - & $\left(N_{\mathrm{Y}} /\left(N_{\mathrm{Y}}+N_{\mathrm{Zr}}\right)\right)=0.17$ & 65 \\
\hline $\mathrm{Fe}$ & 15 & $8 \times 10^{16}$ & $\left(N_{\mathrm{Fe}} /\left(N_{\mathrm{Y}}+N_{\mathrm{Zr}}+N_{\mathrm{Fe}}\right)\right)=0.37$ & 56 \\
\hline $\mathrm{Fe}$ & 50 & $8 \times 10^{16}$ & $\left(N_{\mathrm{Fe}} /\left(N_{\mathrm{Y}}+N_{\mathrm{Zr}}+N_{\mathrm{Fe}}\right)\right)=0.39$ & 50 \\
\hline $\mathrm{Ti}$ & 15 & $8 \times 10^{16}$ & $\left(N_{\mathrm{Ti}} /\left(N_{\mathrm{Y}}+N_{\mathrm{Zr}}+N_{\mathrm{Ti}}\right)\right)=0.30$ & 53 \\
\hline
\end{tabular}

depth of $20 \mathrm{~nm}$, with a maximum $\mathrm{Fe} /(\mathrm{Fe}+\mathrm{Zr}+\mathrm{Y})$ and $\mathrm{Ti} /(\mathrm{Ti}+\mathrm{Zr}+\mathrm{Y})$ ratio of 0.5 and 0.7 , respectively. This $\mathrm{Fe}$ and $\mathrm{Ti}$ depth profile would extend to half of the thickness of the YSZ sputtered layer used in this study. The discrepancy may result from the fact that the RBS spectra of the implanted sputtered YSZ films have been measured after measuring their conductivity. Diffusion of the implanted ions into deeper layers of the sputtered YSZ film during the conductivity measurements might have occurred, giving rise to a broader $\mathrm{Fe}$ and $\mathrm{Ti}$ depth distribution. The composition and thickness of the sputtered films which were used for conductivity measurements are shown in table 1 .

\subsection{Electrical conductivity measurements}

The conductivity of a non-implanted yttria-stabilized zirconia thin film as a function of the temperature is shown in fig. 3 (Arrhenius diagram). In the same figure it is compared with the conductivity of an yttria-stabilized zirconia single crystal of the same composition $\left(\left(\mathrm{ZrO}_{2}\right)_{0.83}\left(\mathrm{YO}_{1.5}\right)_{0.17}\right)$, as determined by Badwal [19]. The conductivity values of the sputtered film are one order of magnitude lower than the single crystal values. In the Arrhenius diagram of the conductivity of the sputtered film a decrease in the activation energy is observed from $(121 \pm 4) \mathrm{kJ} \mathrm{mol}^{-1}$ at $800^{\circ} \mathrm{C}$ to $(76 \pm 4) \mathrm{kJ} \mathrm{mol}^{-1}$ at $400^{\circ} \mathrm{C}$. The conductivity of this yttria stabilized zirconia film is the same in a $\mathrm{H}_{2}$ or $\mathrm{N}_{2}$ atmosphere.

The implantation of the stabilized zirconia film with $15 \mathrm{keV} F e$ up to a dose of $8 \times 10^{16} \mathrm{at.cm}^{-2}$ results in a small decrease of the conductivity of the stabilized zirconia layer in the temperature range of $600-800^{\circ} \mathrm{C}$, as shown in fig. 4 . The activation en-

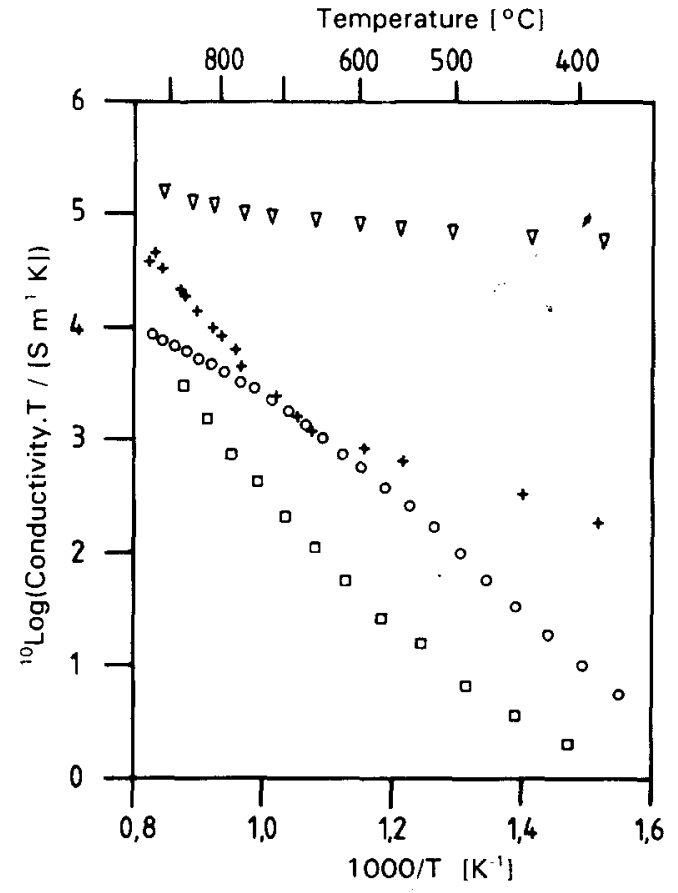

Fig. 3. Conductivity of rf-sputtered yttria-stabilized zirconia (YSZ) thin film $\left(P_{\mathrm{O}_{2}}=1 \times 10^{-5} \mathrm{~atm}\right)$ in comparison with the conductivity of a YSZ single crystal $\left(P_{\mathrm{O}_{2}}=0.21 \mathrm{~atm}, \mathrm{Badwal}\right.$ et al. [17]), pure $\mathrm{Fe}_{2} \mathrm{O}_{3}\left(P_{\mathrm{O}_{2}}=0.21 \mathrm{~atm}\right.$, Warnes et al. [21]) and pure $\mathrm{TiO}_{2-x}\left(\left(P_{\mathrm{CO}} / P_{\mathrm{CO}_{2}}\right)=0.9\right.$, Poumellec et al. [25]). The conductivity values of the YSZ sputtered film and single crystal represent the ionic conductivity, whereas the conductivity values of $\mathrm{Fe}_{2} \mathrm{O}_{3}$ and $\mathrm{TiO}_{2-x}$ represent their $n$-type electronic conductivity: (口) YSZ, thin film (this study); (O) YSZ, single crystal (ref. [19]); (+) $\mathrm{Fe}_{2} \mathrm{O}_{3}$ (ref. [23]); ( $\nabla$ ) $\mathrm{TiO}_{2-x}$ (ref. [27]).

ergy increases from $(121 \pm 4) \mathrm{kJ} \mathrm{mol}^{-1}$ for the nonimplanted film towards $(152 \pm 5) \mathrm{kJ} \mathrm{mol}^{-1}$ for the Fe implanted film. In the temperature range of $400-$ $600^{\circ} \mathrm{C}$ the conductivity is approximately equal to the 


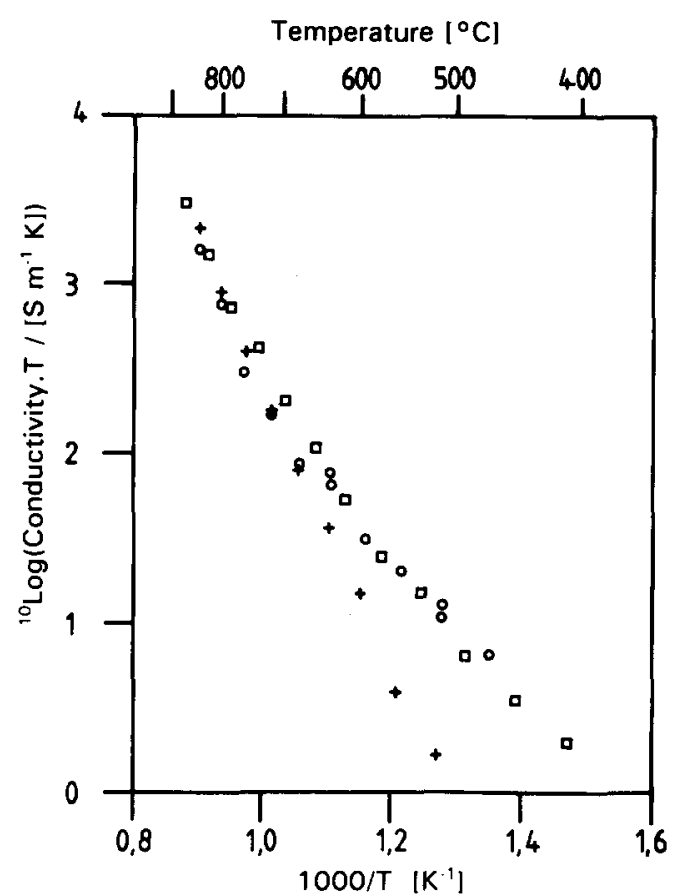

Fig. 4. Conductivity of yttria-stabilized zirconia thin film after the implantation of $15 \mathrm{keV} \mathrm{Fe}$ up to a dose of $8 \times 10^{16} \mathrm{at}^{\mathrm{cm}} \mathrm{cm}^{-2}$ and subsequent oxidation in air at $850^{\circ} \mathrm{C}$, as measured in an atmosphere of either $\mathrm{N}_{2} \quad\left(P_{\mathrm{O}_{2}}=1 \times 10^{-5} \mathrm{~atm}\right)$ or $\mathrm{H}_{2}$ $\left(P_{\mathrm{O}_{2}}=1 \times 10^{-25} \mathrm{~atm}\right)$ gas. The conductivity data for the non-implanted film are shown for comparison: $(\square)$ non-implanted, $\mathrm{N}_{2}$ atmosphere; (O) $15 \mathrm{keV} \mathrm{Fe,} 8 \times 10^{16}$ at. $\mathrm{cm}^{2}, \mathrm{~N}_{2}$ atmmosphere; (+) $15 \mathrm{keV} \mathrm{Fe}, 8 \times 10^{16}$ at. $\mathrm{cm}^{2}, \mathrm{H}_{2}$ atmosphere.

conductivity of the non-implanted film if measured in a $\mathrm{N}_{2}$ atmosphere. The conductivity of the Fe doped film in the temperature range of $400-600^{\circ} \mathrm{C}$ decreases, however, considerably if the sample is reduced at $800^{\circ} \mathrm{C}$ in a $\mathrm{H}_{2}$ atmosphere. After reduction in the $\mathrm{H}_{2}$ atmosphere, a linear Arrhenius diagram is observed with an activation energy of (152 \pm 5$)$ $\mathrm{kJ} \mathrm{mol}^{-1}$ in the whole temperature range of 400 $800^{\circ} \mathrm{C}$.

The implantation of the stabilized zirconia film with $50 \mathrm{keV} \mathrm{Fe}$ up to a dose of $8 \times 10^{16} \mathrm{at}^{\mathrm{cm}} \mathrm{cm}^{-2}$ results also in a decrease in the conductivity of the stabilized zirconia film, as shown in fig. 5 . Both in a $\mathbf{H}_{2}$ and $\mathrm{N}_{2}$ atmosphere a linear Arrhenius diagram is observed in the whole temperature range of $400-800^{\circ} \mathrm{C}$ with an activation energy of $(152 \pm 5) \mathrm{kJ} \mathrm{mol}^{-1}$. This activation energy resembles the activation energy of

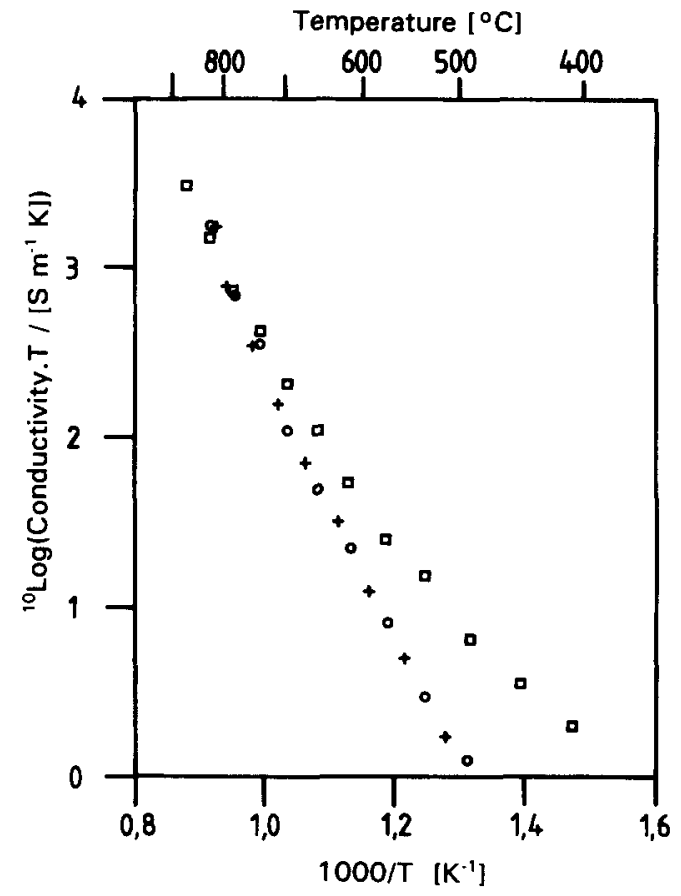

Fig. 5. Conductivity of yttria-stabilized zirconia thin film after the implantation of $50 \mathrm{keV} \mathrm{Fe}$ up to a dose of $8 \times 10^{16} \mathrm{at}^{\mathrm{cm}} \mathrm{cm}^{-2}$ and subsequent oxidation in air at $850^{\circ} \mathrm{C}$, as measured in an atmosphere of either $\mathrm{N}_{2} \quad\left(P_{\mathrm{O}_{2}}=1 \times 10^{-5} \mathrm{~atm}\right)$ or $\mathbf{H}_{2}$ $\left(P_{\mathrm{O}_{2}}=1 \times 10^{-25} \mathrm{~atm}\right)$ gas. The conductivity data for the non-implanted film are shown for comparison: $(\square)$ non-implanted, $\mathbf{N}_{2}$ atmosphere; (O) $50 \mathrm{keV} \mathrm{Fe}, 8 \times 10^{16}$ at. $\mathrm{cm}^{2}, \mathrm{~N}_{2}$ atmosphere; (+) $50 \mathrm{keV} \mathrm{Fe,} 8 \times 10^{16}$ at. $\mathrm{cm}^{2}, \mathrm{H}_{2}$ atmosphere.

the conductivity of the $15 \mathrm{keV} \mathrm{Fe}$ implanted film after reduction in the $\mathrm{H}_{2}$ atmosphere.

The implantation of the stabilized zirconia film with $15 \mathrm{keV}$ Ti up to a dose of $8 \times 10^{16} \mathrm{at}_{\mathrm{cm}} \mathrm{cm}^{-2}$ does not result in a significant change in the conductivity if measured in a $\mathrm{N}_{2}$ atmosphere, as shown in fig. 6 . However, the reduction of the Ti implanted film in $\mathrm{H}_{2}$ at $800^{\circ} \mathrm{C}$ results in an increase of the conductivity with 2-3 orders of magnitude. The activation energy changes from $(121 \pm 4) \mathrm{kJ} \mathrm{mol}^{-1}$ for the nonimplanted film towards $(29 \pm 1) \mathrm{kJ} \mathrm{mol}^{-1}$ for the $\mathrm{Ti}$ implanted sample after reduction in a $\mathrm{H}_{2}$ atmosphere.

\section{Discussion}

The conductivity of the sample, as determined with 


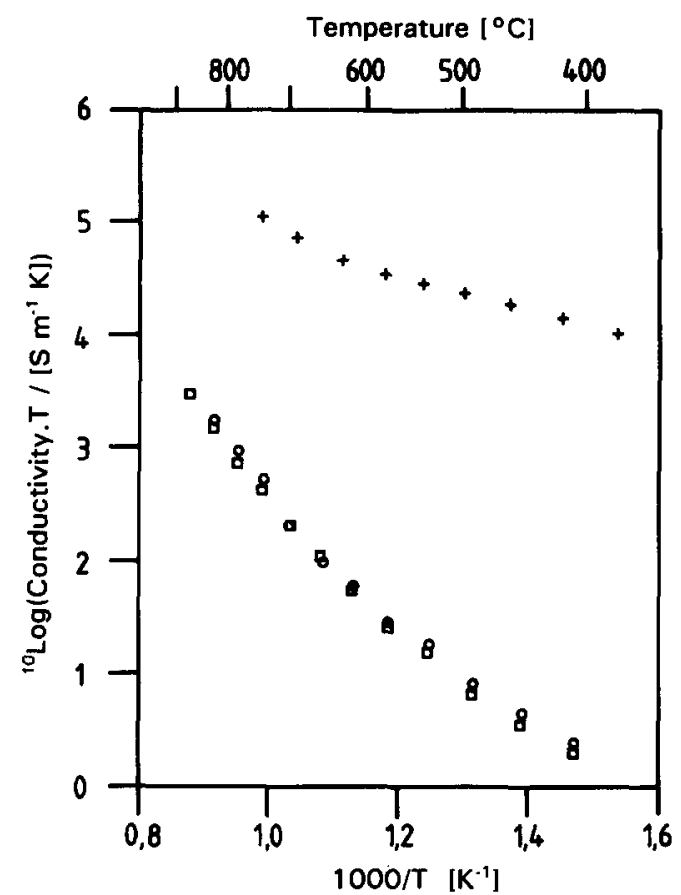

Fig. 6. Conductivity of yttria-stabilized zirconia thin film after the implantation of $15 \mathrm{keV}$ Ti up to a dose of $8 \times 10^{16} \mathrm{at}^{\mathrm{cm}} \mathrm{cm}^{-2}$ and subsequent oxidation in air to $850^{\circ} \mathrm{C}$, as measured in an atmosphere of either $\mathrm{N}_{2} \quad\left(P_{\mathrm{O}_{2}}=1 \times 10^{-5} \mathrm{~atm}\right)$ or $\mathrm{H}_{2}$ $\left(P_{\mathrm{O}_{2}}=1 \times 10^{-25} \mathrm{~atm}\right)$ gas. The conductivity data for the non-implanted film are shown for comparison: $(\square)$ non-implanted, $\mathrm{N}_{2}$ atmosphere; (O) $15 \mathrm{keV} \mathrm{Ti,} 8 \times 10^{16}$ at. $\mathrm{cm}^{2}, \mathrm{~N}_{2}$ atmosphere; (+) $15 \mathrm{keV} \mathrm{Ti,} 8 \times 10^{16}$ at. $\mathrm{cm}^{2}, \mathrm{H}_{2}$ atmosphere.

the four platinum probes, is the sum of both the ionic and electronic conductivity [20]. The two types of conductivity can be discriminated from each other by their oxygen partial pressure dependence. The ionic conductivity of yttria-stabilized zirconia is independent of the oxygen partial pressure, as the oxygen vacancy concentration is fixed by the amount of yttria. The electronic conductivity is, however, strongly dependent on the oxygen partial pressure. The total conductivity may be dominated by one of the two types of conductivity.

The conductivity of the rf-sputtered film of YSZ is independent of the oxygen partial pressure $\left(\mathrm{N}_{2}\left(P_{\mathrm{O}_{2}}=1 \times 10^{-5} \mathrm{~atm}\right)\right.$ versus $\mathrm{H}_{2}\left(P_{\mathrm{O}_{2}}=10^{-25}\right.$ atm )). In this study, this is taken as an indication that the measured conductivity is essentially ionic. Other investigators [2,3] proved this more rigor- ously by measuring the ionic transport number. Values close to unity were obtained for both calcia- and yttria-stabilized zirconia thin films.

The conductivity of the rf-sputtered film of YSZ is one order of magnitude smaller than the conductivity of a single crystal with the same composition. Part of this difference can be explained with the surface roughness of the underlying polycrystalline $\mathrm{Al}_{2} \mathrm{O}_{3}$ substrate. By polishing, a mean surface roughness was obtained of about $50 \mathrm{~nm}$, which is close to the thickness of the sputtered films $(65-108 \mathrm{~nm})$ used in this study. The texture of the sputtered film was not studied, but a poor crystallinity, grain boundaries and porosity will all contribute to a decreased conductivity of the sputtered thin film in comparison with the YSZ single crystal. The change in activation energy of $E_{\text {act }}=(76 \pm 4) \mathrm{kJ} / \mathrm{mol}\left(400-600^{\circ} \mathrm{C}\right)$ to $E_{\text {act }}=(121 \pm 4) \mathrm{kJ} / \mathrm{mol}\left(600-800^{\circ} \mathrm{C}\right)$ is in the opposite direction as the change in ionic conductivity of polycrystalline YSZ bulk materials [21]. No explanation for this effect can be given so far.

The implantation of $15 \mathrm{keV} \mathrm{Fe}$ up to a dose of $8 \times 10^{16}$ at.cm ${ }^{-2}$ results after oxidation in air in a stabilized zirconia layer with approximately the same conductivity as the non-implanted layer. This result implies that the increased conductivity of a stabilized zirconia film after the implantation of Fe up to a dose of $8 \times 10^{16}$ at.cm ${ }^{-2}$, as observed by Scholten [22], could not be reproduced. This discrepancy might result from a different thermal history of the sample. As observed in RBS spectra of the Fe implanted film, some redistribution of the implanted Fe atoms towards deeper layers takes place during the conductivity measurements. The thickness of the YSZ films used in the conductivity measurements of our study $(60 \mathrm{~nm})$ was somewhat smaller than the film thickness used by Scholten $(100 \mathrm{~nm})$. So changes in the conductivity of the $\mathrm{Fe}$ implanted film would have been more easily observed in our study. But also the measurement technique has been improved. The small current (only several nA) has been measured more accurately. The conductivity was no longer measured during heating of the sample but after a thermal equilibration of a few hours. In the present study the conductivity of the sample has been determined from the slope of the steady state current versus potential plot. Scholten [22] determined the conductivity from a single measurement of the cur- 
rent and the corresponding potential, neglecting a possible offset voltage. More careful analysis showed the offset voltage to be too large to be ignored.

The conductivity of the Fe implanted film is, however, different from the conductivity of the non-implanted film in respect to its oxygen partial pressure dependence. The conductivity of the $\mathrm{Fe}$ implanted film in the temperature range of $400-600^{\circ} \mathrm{C}$ significantly decreases after reduction in a $\mathrm{H}_{2}$ atmosphere. This was not observed for the non-implanted film.

In view of the results obtained previously, the outermost surface of this Fe implanted stabilized zirconia layer will mainly consist of $\mathrm{Fe}_{2} \mathrm{O}_{3}$ with an approximate thickness of $2 \mathrm{~nm}[17,18]$. Pure $\mathrm{Fe}_{2} \mathrm{O}_{3}$ is an $n$-type semiconductor [23] below $800^{\circ} \mathrm{C}$ and its conductivity is determined by electronic charge carriers. Its electronic conductivity is somewhat larger than the ionic conductivity of stabilized zirconia, as indicated in fig. 3. Due to the limited extent of this $\mathrm{Fe}_{2} \mathrm{O}_{3}$ layer, it will contribute only little to the total conductivity of the stabilized zirconia film. But especially in the low temperature region, it may dominate over the ionic conductivity.

The reduction of this $\mathrm{Fe}$ implanted sample in $\mathrm{a}_{2}$ atmosphere will result in a reduction of the $\mathrm{Fe}_{2} \mathrm{O}_{3}$ layer towards metallic Fe. The microstructure of this layer is not known but in a similar experiment performed on $\mathrm{Fe}$ implanted $\mathrm{Al}_{2} \mathrm{O}_{3}$ it was shown that metallic $\mathrm{Fe}$ particles were formed which were not connected [24]. In the "as-implanted" state of Fe implanted YSZ metallic Fe precipitates have been identified by Scholten [22] and Burggraaf et al. [14], using Conversion Electron Mössbauer Spectroscopy. Hence the conducting surface layer of $\mathrm{Fe}_{2} \mathrm{O}_{3}$ is lost. If the precipitates are not connected this will result in a decrease of the conductivity of the Fe implanted film.

$\mathrm{Fe}^{3+}$ can be substitutionally incorporated for $\mathrm{Zr}^{4+}$ in the stabilized zirconia lattice up to $7 \mathrm{~mol} \% \mathrm{Fe}_{2} \mathrm{O}_{3}$ [22], which corresponds to a cation fraction of 0.15 . Precipitation of small $\mathrm{Fe}_{2} \mathrm{O}_{3}$ particles occurs when the concentration corresponding, to this solubility level is exceeded. The mean concentration of $\mathrm{Fe}$ in the sputtered film, as shown in table 1, exceeded the Fe concentration corresponding to its solubility level (cation fraction of 0.15 ). Thus part of the implanted $\mathrm{Fe}$ can be expected to form $\mathrm{Fe}_{2} \mathrm{O}_{3}$ precipitates in an oxidizing atmosphere. The dissolution of $\mathrm{Fe}_{2} \mathrm{O}_{3}$ in the YSZ lattice results in oxygen vacancies in the oxygen sublattice according to the following incorporation reaction (Kröger-Vink notation):

$\mathrm{Fe}_{2} \mathrm{O}_{3} \rightleftharpoons 2 \mathrm{Fe}_{\mathrm{Zr}}^{\prime}+3 \mathrm{O}_{\mathrm{O}}^{\times}+\mathrm{V}_{\mathrm{O}}$.

Such an increase in oxygen vacancy concentration may in principle result in an increase of the ionic conductivity of the stabilized zirconia film. This is, however, only true in the case of low dopant concentrations. When the dopant concentration increases an optimum is reached whereafter the conductivity starts to decrease [25]. At the same time an increase in the activation energy is observed. Due to the doping with $\mathrm{Y}_{2} \mathrm{O}_{3}$, an oxygen vacancy concentration was present in the stabilized zirconia film close to this optimum in the ionic conductivity. Hence, further doping with other three-valent cations will result in a decrease of the conductivity and an increase in the activation energy. Both the reduction of the $\mathrm{Fe}_{2} \mathrm{O}_{3}$ layer towards not interconnected metallic $\mathrm{Fe}$ precipitates and the optimum which is present in the ionic conductivity of YSZ as a function of the dopant concentration can explain the decrease in conductivity in the range of 400 $600^{\circ} \mathrm{C}$ in the Arrhenius-diagram of fig. 4, followed by a simultaneous increase of the activation energy.

The implantation of $50 \mathrm{keV} \mathrm{Fe}$ up to a dose of $8 \times 10^{16}$ at.cm $^{-2}$ results in a gaussian depth profile under the surface of the stabilized zirconia film with a mean projected range of $19 \mathrm{~nm}$ and range straggling of $8.5 \mathrm{~nm}$. The stabilized zirconia film is more uniformly doped due to the larger mean projected range and range straggling of the implanted $\mathrm{Fe}$ atoms in comparison with the $15 \mathrm{keV} \mathrm{Fe}$ implantation. No surface layer of $\mathrm{Fe}_{2} \mathrm{O}_{3}$ is expected to be present. Both in a $\mathrm{N}_{2}$ and $\mathrm{H}_{2}$ atmosphere a decrease in the conductivity in combination with an increase in the activation energy is observed in comparison with the non-implanted YSZ layer. This can be explained with the same argument as discussed for the case of the $15 \mathrm{keV} \mathrm{Fe}$ implanted layer. Once again a dopant concentration is reached beyond the optimum in the curve of ionic conductivity versus dopant concentration.

In view of the results obtained previously $[17,18]$, the outermost surface layer of the Ti implanted sample will mainly consist of $\mathrm{TiO}_{2}$. Just below this surface layer, the stabilized zirconia layer is doped with 
Ti up to a depth of $18 \mathrm{~nm}$ and with a maximum cation fraction of $\mathrm{Ti}$ of about 0.70 . $\mathrm{TiO}_{2}$ can be substitutionally incorporated for $\mathrm{Zr}$ in the stabilized zirconia lattice up to $15 \mathrm{~mol} \%[10,26]$. Precipitation of $\mathrm{ZrTiO}_{4}$ was observed in ceramic yttria-stabilized zirconia samples if the $\mathrm{TiO}_{2}$ concentration exceeded the concentration corresponding to this solubility level [26], but not yet for Ti implanted YSZ. The mean concentration of $\mathrm{Ti}$ in the sputtered film, as shown in table 1, exceeds the Ti concentration corresponding to the solubility level of $\mathrm{TiO}_{2}$ in YSZ. From the conductivity measurements it can, however, be concluded that neither the incorporation of $\mathrm{TiO}_{2}$, nor the expected precipitation of $\mathrm{ZrTiO}_{4}$ did apparently result in a change in the conductivity of the YSZ layer if measured in a $\mathrm{N}_{2}$ atmosphere.

The reduction of the $\mathrm{Ti}$ implanted layer resulted in a remarkable increase in the conductivity with 23 orders of magnitude. This may result from the formation of a layer of nonstoichiometric $\mathrm{TiO}_{2-x}$, which is an $n$-type semiconductor [27]. The conductivity of $\mathrm{TiO}_{2-x}$ has been indicated in fig. 3 for comparison. A large increase in mainly electronic conductivity can indeed be expected. It may also result from the reduction of that part of Ti that is incorporated substitutionally for $\mathrm{Zr}$ in the YSZ lattice. In this view, the $\mathrm{Ti}^{4+}$ states, which act as electron acceptors when empty, are filled upon reduction, i.e. the forming of $\mathrm{Ti}^{3+}$. At sufficiently high concentrations of these (acceptor-)states, an impurity band can form, resulting in an increase of the conductivity of the $\mathrm{Ti}$ implanted YSZ film. Furthermore, when Ti is incorporated for $\mathrm{Zr}$ in the YSZ lattice this may result in a decrease of the bandgap. This effect is presently under investigation [28]. Previously this effect has been observed in the system $\mathrm{SrZrO}_{3}$ [29]. In strongly reduced $\mathrm{Ti}$-doped $\mathrm{YSZ}$ the $\mathrm{Ti}^{3+}$ states may then act as electron donors, increasing the concentration of conduction band electrons and hence increasing the electronic conductivity.

\section{Conclusions}

Rf-sputtering of yttria-stabilized zirconia (YSZ) resulted in thin films with an ionic conductivity which has one order of magnitude lower than the conductivity of YSZ in a single crystal form. This is ascribed to the microstructure of the sputtered film.

The implantation of $15 \mathrm{keV}$ or $50 \mathrm{keV} \mathrm{Fe}$ up to a dose of $8 \times 10^{16} \mathrm{at}_{\mathrm{cm}} \mathrm{cm}^{-2}$, and subsequent oxidation of the implanted layer in air results in a decrease in ionic conductivity and an increase in its activation energy. This has been explained by the incorporation of part of the implanted $\mathrm{Fe}$ atoms as $\mathrm{Fe}^{3+}$ on a $\mathrm{Zr}^{4+}$ lattice position in the YSZ lattice.

The conductivity of the $15 \mathrm{keV} \mathrm{Fe}$ implanted layer is oxygen partial pressure dependent in the temperature range of $400-600^{\circ} \mathrm{C}$. This can be ascribed to the presence of an $\mathrm{Fe}_{2} \mathrm{O}_{3}$ layer (thickness $<2 \mathrm{~nm}$ ) on top of the sputtered YSZ thin film. In this low temperature region, the $n$-type electronic conductivity of $\mathrm{Fe}_{2} \mathrm{O}_{3}$ dominates the ionic conductivity of the underlying YSZ sputtered film.

The implantation of $15 \mathrm{keV} \mathrm{Ti}$ up to a dose of $8 \times 10^{16}$ at.cm $^{-2}$ does not result in a significant change in the total conductivity of the YSZ thin film if measured in an oxidized state. After reduction in a $\mathrm{H}_{2}$ atmosphere at $800^{\circ} \mathrm{C}$, an increase in conductivity is observed with 2-3 orders of magnitude. This large increase in conductivity can be ascribed to the $n$-type conductivity of nonstoichiometric $\mathrm{TiO}_{2-x}$.

\section{Acknowledgement}

The authors appreciate the cooperation with the Laboratorium voor Algemene Natuurkunde (LAN) of the State University of Groningen. They are grateful to J.J. Smit for the ion implanter facilities. They thank Dr. D.O. Boerma of the State University of Groningen for his supervision during the RBS measurements. They are indebted to H.W. Krabbe of the University of Twente for preparing the thin film samples. The investigations were supported by the Netherlands Foundation for Chemical Research (SON) with financial aid from the Netherlands Organisation for Scientific Research (NWO).

\section{References}

[1] W.L. Worrell, Solid Electrolytes, Topics in Applied Physics, Vol. 21, ed. S. Geller (Springer, Berlin, 1977) pp. 143-168.

[2] M. Croset, J.P. Schnell and G. Velasco, J. Appl. Phys. 48 (1977) 775 . 
[3] J.P. Schnell, M. Croset, D. Dieumegard, G. Velasco and J. Siejka, Nucl. Instrum. Methods 209/210 (1983) 1187.

[4] A.O. Isenberg, ESC Symp. Electrode Materials, Processes for Energy Conversion and Storage, Vol. 77-6 (1977) pp. 572-583.

[5] Y.S. Lin, L.G.J. de Haart, K.J. de Vries and A.J. Burggraaf, in: Euro-Ceramics, eds. G. de Width, R.A. Terpstra and R. Metselaar, Vol. 3 (Elsevier, London, 1989) pp. 3.590-595.

[6] E.C. Subbarao and H.S. Maiti, Solid State Ionics 11 (1984) 317.

[7] M.P. van Dijk, Ordering, electrical conductivity and electrode properties of ceramics with fluorite related structures, PhD Thesis (University of Twente, Enschede, The Netherlands, 1985).

[8 ] M.P. van Dijk, K.J. de Vries and A.J. Burggraaf, Solid State Ionics 21 (1986) 73.

[9] Y. Takasu, T. Sugini and Y. Matsuda, J. Appl. Electrochem. 14 (1984) 79.

[10] S.S. Liou and W.L. Worrell, Appl. Phys. A 49 (1989) 25.

[11] L.J. Olmer, J.C. Viguie and E.J.L. Schouler, Solid State Ionics 7 (1982) 23.

[12] D. Scholten and A.J. Burggraaf, Solid State Ionics 16 (1985) 147.

[13] B.A. van Hassel and A.J. Burggraaf, Appl. Phys. A 49 (1989) 33.

[14] A.J. Burggraaf, D. Scholten and B.A. van Hassel, Nucl. Instrum. Methods in Phys. Res. B 32 (1988) 32.

[15] H. Kruidhof, Internal report CT85/350/128 (University of Twente, 1985).

[16] Wei-Kan Chu, J.W. Mayer and M.-A. Nicolet, Backscattering Spectrometry (Academic Press, New York, 1978).
[17] B.A. van Hassel and A.J. Burggraaf, Appl. Phys. A 53 (1991) 155.

[18] B.A. van Hassel, Transport and oxygen transfer properties of ion implanted yttria stabilized zirconia, $\mathrm{PhD}$ Thesis (University of Twente, Enschede, The Netherlands, 1990).

[19] S.P.S. Badwal, J. Mater. Sci. 19 (1984) 1767.

[20] G.J. Dudley and B.C.H. Steele, J. Solid State Chem. 31 (1980) 233.

[21 ] M.J. Verkerk, B.J. Middelhuis and A.J. Burggraaf, Solid State Ionics 6 (1982) 159.

[22] D. Scholten, Surface modification of yttria stabilized zirconia by ion implantation, $\mathrm{PhD}$ Thesis (University of Twente, Enschede, The Netherlands, 1987).

[23] B.M. Warnes, F.F. Aplan and G. Simkovich, Solid State Ionics 12 (1984) 271.

[24] C.J. McHargue, G.C. Farlow, P.S. Sklad, C.W. White, A. Perez, N. Kornilios and G. Marest, Nucl. Instrum. Methods in Phys. Res. B 19/20 (1987) 813.

[25] A.I. Ioffe, D.S. Rutman and S.V. Karpachov, Electrochim. Acta 23 (1978) 141.

[26] B.A. van Hassel, Phase stability of $\mathrm{TiO}_{2}$ doped yttria stabilized zirconia, unpublished work.

[27] B. Poumellec, J.F. Marucco and F. Lagnel, Phys. Status Solidi (a) 89 (1985) 375.

[28] U. Vohrer, H.-D. Wiemhöfer, W. Göpel, B.A. van Hassel and A.J. Burggraaf, to be published.

[29] L.G.J. de Haart, K.J. de Vries and G. Blasse, J. Solid State Chem. 59 (1982) 291. 